\title{
Research on Intelligent Logistics Talent Cultivation in Emerging Engineering Construction
}

\author{
Ge Dong-yuan ${ }^{1}$, Wei Jian-jun ${ }^{1}$, Luo Hui-cong ${ }^{2}$, Luo Hai-ping ${ }^{1}$, Liang Shuang-yi ${ }^{1}$ \\ 1. College of mechanical engineering, Guangxi University of Science and Technology \\ 2. Longhui Second Middle School of Hunan Province
}

\begin{abstract}
According to the fact that artificial intelligence is widely used in the logistics industry but domestic logistics talents relatively lag behind in terms of artificial intelligence, this research will focus on training students for intelligent logistics throughout the construction of emerging engineering so as to enable students to be equipped with scientific literacy and professional ability. The development of the teaching reform project will provide a new perspective and a new dimension for cultivating intelligent logistics talents in the context of emerging engineering construction.
\end{abstract}

Keywords-Emerging engineering; Intelligent logistics; Talent cultivation

\section{INTRODUCTION}

The logistics industry is an emerging polymer industry with broad development prospect; when a country's economy becomes more developed, its logistics industry will become more advanced; and the promotion of "the Internet plus logistics" initiative can help develop the new economy as well as enhance the traditional economy. With promotion and application of the Internet of Things and AI (artificial intelligence), as well as the deep integration of Internet, mobile Internet, big data, cloud computing into the logistics industry, the logistics is becoming increasingly intelligent. In December 2016, Ding Hongwei, Principal Data Scientist of Cainiao Network Technology Co., Ltd, proclaimed that big data endowed wings for intelligent logistics [1]. In the era of big data when intelligent logistics serves as one of the important branches of the big data system of logistics, the new business model of $\mathrm{O} 2 \mathrm{O}$ (Online To Offline) requires intelligent logistics [2]. The "intelligent" development of logistics is more conducive to building an efficient, transparent, and information-symmetric modern logistics system. "Emerging engineering education" directs at emerging industries, which refers to not only such majors for emerging industries as artificial intelligence, intelligent manufacturing, robotics, and cloud computing, but also the upgrading of traditional engineering majors. From the view of the new economy, the novelty of the emerging engineering education" lies in the new requirements for future development of engineering disciplines in China. The development of the new industries needs innovative education to cultivate new talents and upgrade the service industry. The Ministry of Education held a seminar on advanced engineering education development at Fudan University and reached the Fudan Consensus in February 2017; it held a seminar on the construction of emerging engineering at Tianjin University in April 2017, clarifying the action guide for emerging engineering. In June 2017, the Ministry of Education set up the expert group for emerging engineering research and practice and convened the first working meeting of the expert group in Beijing, reviewing and approving the "Guidelines for Emerging Engineering Research and Practice Projects" [3-4]. The Fudan Consensus, the Tianjin University Action, and the Beijing Guidelines constitute the "trilogy" of the emerging engineering and blaze a trail for the engineering education reform

The rapidly growing demand for logistics service in mainland China will inevitably bring about a sharp increase in demand for logistics technicians. However, several weaknesses remain in the theoretical research and the training of logistics professionals in China. This is because logistics technology and its related theories do not be given due attention, as well as artificial intelligence and other latest achievements are not been fully utilized. This research subject explores and carries out the training program for logistics technicians with artificial intelligence as their professional background by means of the platform of the "Emerging Engineering Education".

\section{Status Analysis OF LOGISTICs PROFESSIONAL TRAINING}

Relatively speaking, mainland China lags behind in the development of the logistics industry and accordingly, the related discipline construction starts late. Some universities lack complete infrastructure so as to hinder the discipline construction and the professional development. In view of the rapid development of the logistics industry, the state has increased investment in the industry; some related universities and teachers are conducting various education reforms and teaching research activities to explore the training system of advanced logistics talents for enterprises. For example, Wuhan University of Technology, as one of the first universities to establish the logistics discipline, can grant the master and doctoral degrees of "Logistics Engineering" and "Logistics Management". The university has the capacity to independently undertake such research tasks as the key technologies of port logistics, the automation and intelligent control of logistics equipment, as well as planning and simulation of the logistics system, thereby cultivating a large number of senior logistics professionals [5]. Dalian University of Technology adopts the " $2+2$ " training model, that is, 
students learn the basic theory of engineering in first two years and then study professional courses of logistics management in the remaining two years. This traditional teaching model of "static training" is limited to the theory teaching in classroom, and has loose practice and teaching management. Because practical teaching does not serves the theory teaching in classroom effectively, the theoretical study of the logistics technology becomes abstract and empty, theory deviating from practice, even giving people the illusion of belittling the practical teaching.

\section{A. The Lack of Teachers with both Theoretical and Practical Experience}

The logistics major has a strong practicality across multiple industry sectors and involving many links. It requires teachers to have solid professional theoretical knowledge and strong practical skills. Relatively speaking, most second-rate colleges and vocational and technical colleges have problems such as the unbalanced teaching ability, the incomplete academic echelon, and the lack of academic leaders with higher academic standards. Most college teachers of the logistics major are employed by colleges as soon as they graduate from school without any practical experience so that they have a certain theoretical knowledge but are short of enterprise practice experience. It is hard for them to combine theoretic teaching with engineering practice, and to expand and deepen the theoretical teaching, thereby influencing the overall teaching effect.

\section{B. Misunderstanding in Theoretical and Practical Teaching}

Mainland China is a late starter in the logistics industry, and at the same time, some universities do not invest enough or give due attention in practical teaching. Though the experimental conditions are superior in some universities, they do not receive attention from teachers and schools. Students uphold the thought of doing experiments for the single purpose without verifying and consolidating their theoretical knowledge through experiments so that their theoretical learning can not be promoted greatly. In the face of the new economy and new technologies, the training for students' creative ability still lacks pertinence and has not combined the cultivation of innovation and entrepreneurship for students in the context of intelligent logistics.

\section{Problems in the Curriculum System}

The Internet plus logistics, cloud computing, the Internet of things, and big data have brought unprecedented opportunities for the logistics industry development, while the teaching content of professional courses has not been updated timely. Some new business models based on information technology and new logistics engineering cases based on machine learning have not been introduced into classroom teaching in the way that students can accept; they don't adapt to students' preliminary understanding for frontier research and development of logistics. The old teaching content is difficult to arouse students' interest in professional learning or train their innovative ideas that must be possessed by scientific workers.

\section{Poor Quality in the Practice Part of Graduation Papers (Projects)}

Graduation papers (graduation projects) are an important part to realize the goal of training logistics talents, cultivating students' awareness of innovation, and enhancing their ability to solve practical problems. However, most graduation papers and projects have problems like old topics, lacking application background, and loose combination with engineering practice and the frontier research of logistics technology. As a result, students' theoretical knowledge cannot be fully reflected and applied in graduation papers (projects), and their professional abilities cannot be expanded [6-7].

\section{TEACHING REFORM OF INTELLIGENT LOGISTICS} TALENTS FOR THE EMERGING ENGINEERING CONSTRUCTION

\section{A. Discipline Construction for Emerging Engineering}

Against the background of the emerging engineering construction, this paper makes full use of the orderly profession development in discipline construction, the gradual improvement of teachers' ability, and the increasing attention from schools to the logistics major with the help of the project support and technology guidance(including National Natural Science Foundation Project: Research on Several Key Technologies of Precision Testing Based on Machine Learning (51765007)) on the basis of group members' research on logistics technology and artificial intelligence. Teachers should appropriately introduce the frontier research and the application of machine learning to show students the trends and prospects of the logistics industry by consciously combining their knowledge in artificial intelligence. Through researches of the group, carry out scientific research and teaching reform activities based on the big data technology to gradually narrow the gap with schools having long history and excellent conditions, ease the weak scientific research capabilities in disciplinary development, and realize knowledge inheritance and innovation as well as accumulation of discipline advantages.

\section{B. Cultivation of Students' Innovative Ability for Emerging Engineering}

Emerging engineering construction that serves the new economy and the new technologies needs to combine domestic and foreign frontier research on artificial intelligence, and the specialized courses should aim at cultivating students' independent innovation capabilities. Students should be enlightened in teaching process and have more opportunities to put forward their unique insights so as to master basic theories of the logistics technology. With strong theoretical characteristics of logistics professional courses, the contents and programs of experimental teaching should be designed according to the teaching content, allowing students to do an experiment on the basis of their questions and guiding them to use the theoretical knowledge they learned to solve problems. [8] Students should realize that the theoretical learning is the foundation for the professional learning no matter how the logistics technology develops. The relevance and versatility of advanced theories helps students develop their knowledgetransfer capability in different areas through technological and 
method innovation on a solid theoretical basis, thereby growing into talents with innovation capabilities in intelligent logistics.

\section{Teaching Ideas like Students' Cross-border Thoughts for Emerging Engineering}

With the wide application of artificial intelligence in various industries and fields, the boundaries of many industries are blurred. Some new models, such as the "NTOCC" model, the "O2O" model, the "Internet + Logistics + Finance" model, and the whole-supply chain information system model, have realized the integration of the logistics industry, the financial industry, and the Internet. These models are the focus of the training of smart logistics talents in various universities and enabling these talents to have the ability to integrate disciplines.

\section{Improvements of Teaching Content for Emerging Engineering}

In the context of the new technologies and the new economy, the Internet of Things, mobile APP, big data, and cloud computing will be deeply integrated with the logistics industry, which accelerates the "intelligent development" of the logistics industry and brings profound changes to the industry, such as using mobile APP to obtain the multidimensional portrayal of human behavior data. The use of RFID technology can not only track goods and ensure safety, but also discover business opportunities through big data, which shows that the attractive objective facts and development prospects of the logistics industry. Therefore, the teaching reform of the logistics major for emerging engineering construction needs to update teaching content timely, introduce relevant intelligent logistics technologies into teaching, and strengthen the role of professional background of artificial intelligence in the training of logistics professionals. At the same time, in the teaching process of graduation papers (projects), topics can include such freight O2O platforms as RenRen Express, Yunniao Delivery, Magical Delivery, Blessing Truck, Truck Alliance, and EasyVan. What's more, logistics cases based on drones, intelligent express, 3D printing and big data can be employed as paper (project) topics to make up for students' weaknesses in professional learning, thereby solving the problems of innovation shortage and theoretical knowledge in talents training.

\section{CONCLUSION}

In the context of deep integration of artificial intelligence with engineering practice, taking the emerging engineering construction as the platform, this project explores training programs for intelligent logistics talents from the aspects of discipline construction, innovative education, teaching ideas and content so as to foster students' ability to find and solve problems, think independently and study for life, thereby providing a new dimension for the "Emerging Engineering Education" model and promoting intelligent development of China's logistics technology.

\section{ACKNOWLEDGMENT}

The work described in this paper is partially supported by the National Natural Science Foundation of China under grant No. 51765007, Undergraduate Teaching Reform Project of Guangxi Higher Education (2018JGA204), and 2018 Project Planning of Logistics Teaching Reform and Teaching Research of China Society of Logistics (No. JZW2018037). The authors also gratefully acknowledge the suggestions of the reviewers, which helped to improve the presentation.

\section{REFERENCES}

[1] [EB/OL].https://www.wenji8.com/p/7a4N7oD.html. Deep | How to Enjoy Intelligent logistics in Big Data times/Age? [EB/OL].https://www.wenji8.com/p/7a4N7oD.html.

[2] SUN Zhi-wei. O2O Coping Strategies in the Age of Big Data Logistics Industry [J]. Logistics Sci-Tech, 2014, No.9, 70-73.

[3] HU Bo, FENG Hui, HAN Wei-li, et al. Accelerating the Establishment of New Engineering and Technical Disciplines and Promoting the Innovation in Engineering Education: A Review of the Symposium on the Strategy of Developing Higher Engineering Education [J]. Fudan Education Forum, 2017, Vol.15, No.2, 20-27+2.

[4] [Xia Jiang-guo, Zhao Jun. On the Reform and Development of Engineering Education in Local Universities and Colleges Based on Establishing Emerging Engineering Education [J]. Research in Higher Education of Engineering, 2017, No.3,15-19+65

[5] ZHANG Qing-ying, ZHANG Ying, LUO Shu-quan, et al. Knowledge Innovation in the Process of Case Teaching [J]. Logistics Engineering and Management. 2010, 32(2): 119-120.

[6] LUO Yanfang, CHEN Ailing. Research on Experiment Teaching System of Logistics Management Education Based on Intelligent logistics Lab [J]. Logistics Sci-Tech, 2017, No. 12, 138-140.

[7] Wang Xuefeng, Yang Fang. Study on Innovative Practical Teaching System of Logistics Management Specialty Based on Disciplinary Competition [J]. Logistics Technology, 2017, 36(4):174-178.

[8] LIU Zhi-ping, ZHANG Qing-ying, ZHANG Ying. The Logistics Major Reforming of Teaching Practices under Wide Open View [J]. Logistics Engineering and Management. 2015, 37(4): 168-169+8. 